\title{
Reevaluation of Mineral aerosol radiative forcings suggests a better agreement with satellite and AERONET data
}

\author{
Y. Balkanski ${ }^{1}$, M. Schulz ${ }^{1}$, T. Claquin ${ }^{1, *}$, and S. Guibert ${ }^{1}$ \\ ${ }^{1}$ Laboratoire des Sciences du Climat et de l'Environnement, 91190 Gif-sur-Yvette Cedex, France \\ *now at: CDC IXIS CAPITAL MARKETS, Paris, France
}

Received: 27 March 2006 - Published in Atmos. Chem. Phys. Discuss.: 1 September 2006

Revised: 20 November 2006 - Accepted: 8 December 2006 - Published: 10 January 2007

\begin{abstract}
Modelling studies and satellite retrievals do not agree on the amplitude and/or sign of the direct radiative perturbation from dust. Modelling studies have systematically overpredicted mineral dust absorption compared to estimates based upon satellite retrievals. In this paper we first point out the source of this discrepancy, which originates from the shortwave refractive index of dust used in models. The imaginary part of the refractive index retrieved from AERONET over the range 300 to $700 \mathrm{~nm}$ is 3 to 6 times smaller than that used previously to model dust. We attempt to constrain these refractive indices using a mineralogical database and varying the abundances of iron oxides (the main absorber in the visible). We first consider the optically active mineral constituents of dust and compute the refractive indices from internal and external mixtures of minerals with relative amounts encountered in parent soils. We then compute the radiative perturbation due to mineral aerosols for internally and externally mixed minerals for 3 different hematite contents, $0.9 \%, 1.5 \%$ and $2.7 \%$ by volume. These constant amounts of hematite allow bracketing the influence of dust aerosol when it is respectively an inefficient, standard and a very efficient absorber. These values represent low, central and high content of iron oxides in dust determined from the mineralogical database. Linke et al. (2006) determined independently that iron-oxides represent 1.0 to $2.5 \%$ by volume using $\mathrm{x}$-Ray fluorescence on 4 different samples collected over Morocco and Egypt. Based upon values of the refractive index retrieved from AERONET, we show that the best agreement between 440 and $1020 \mathrm{~nm}$ occurs for mineral dust internally mixed with $1.5 \%$ volume weighted hematite. This representation of mineral dust allows us to compute, using a general circulation model, a new global estimate of mineral dust perturbation between -0.47 and $-0.24 \mathrm{Wm}^{-2}$ at the top of the atmosphere, and between -0.81 and $-1.13 \mathrm{Wm}^{-2}$
\end{abstract}

Correspondence to: Y. Balkanski

(yves.balkanski@cea.fr) at the surface for both shortwave and longwave wavelengths. The anthropogenic dust fraction is thought to account for between 10 and $50 \%$ of the total dust load present in the atmosphere. We estimate a top of the atmosphere forcing between -0.03 and $-0.25 \mathrm{Wm}^{-2}$, which is markedly different that the IPCC range of -0.6 to $+0.4 \mathrm{Wm}^{-2}$ (IPCC, 2001). The 24-h average atmospheric heating by mineral dust during summer over the tropical Atlantic region $\left(15^{\circ} \mathrm{N}-25^{\circ} \mathrm{N}\right.$; $45^{\circ} \mathrm{W}-15^{\circ} \mathrm{W}$ ) is in the range +22 to $+32 \mathrm{Wm}^{-2} \tau^{-1}$ which compares well with the $30 \pm 4 \mathrm{Wm}^{-2} \tau^{-1}$ measured by Li et al. (2004) over that same region. The refractive indices from Patterson et al. (1977) and from Volz (1973) overestimate by a factor of 2 the energy absorbed in the column during summer over the same region. This discrepancy is due to too large absorption in the visible but we could not determine if this is linked to the sample studied by Patterson et al. (1997) or to the method used in determining the refractive index.

\section{Introduction}

Dust radiative forcing has been singled out as one of the largest uncertainties in assessing anthropogenic radiative forcing (IPCC, 2001). There is still debate on the overall sign of this forcing. The less well known aspects of the dust cycle are: first, the part of the airborne dust that is anthropogenic, second, how absorbing dust really is. The first investigation that drew into question the absorption of dust in modelling papers is the work of Kaufman et al. (2001). These authors examined the contrast of two dusty situations off the coast of Africa when optical depth reached 0.8 and 2.4 at $640 \mathrm{~nm}$. The imaginary part of the dust refractive index was varied for these two cases until it fitted the radiances computed from the surface reflectance at satellite level. The increase in apparent reflectance that is consistent for the whole area of study suggested that dust is close to non-absorbing. Independently, Moulin et al. (2001) noticed

Published by Copernicus GmbH on behalf of the European Geosciences Union. 

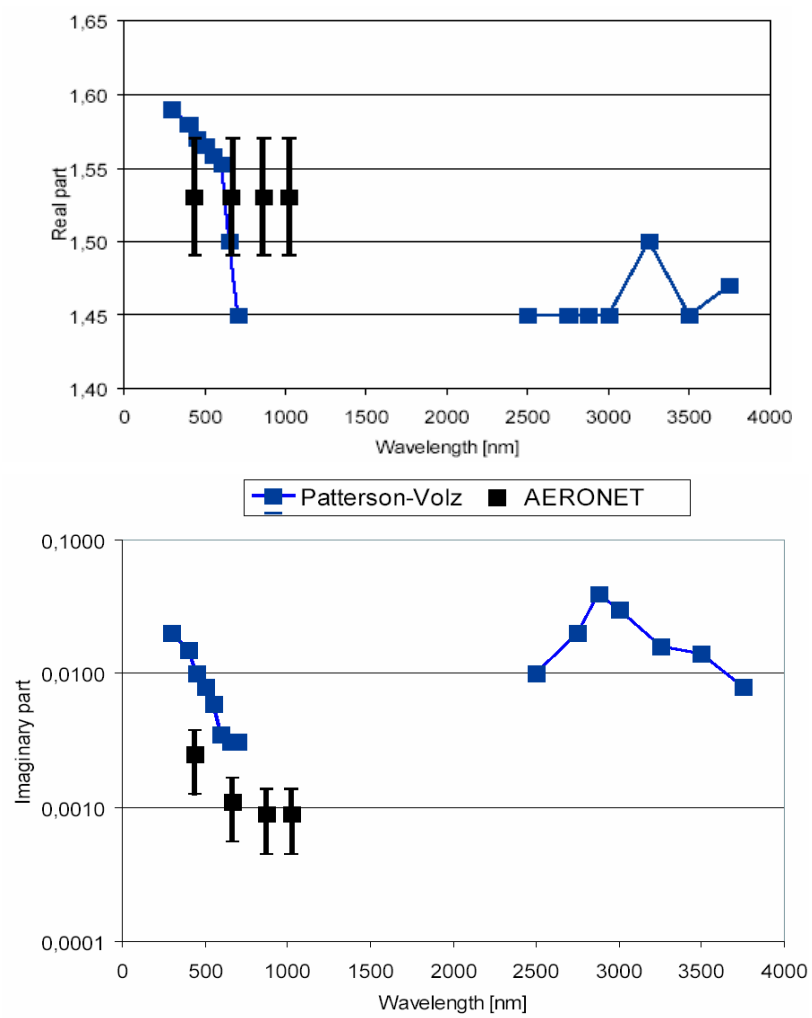

Fig. 1. Real and imaginary parts of mineral aerosol refractive indices. The filled blue squares indicate measurements that were collected by Patterson et al. (1977) between 300 and $700 \mathrm{~nm}$ and by Volz (1973) for wavelengths greater than $2500 \mathrm{~nm}$. The AERONET measurements shown by the black squares are the ones reported by Dubovik et al. (2002). Uncertainties are \pm 0.04 on the real part of the refractive index and 50\% on the imaginary part (Dubovik, 2002, and personal communication). The case that we refer to as $S 2$ or Patterson-Volz consists of a linear interpolation between the wavelengths 700 and $2500 \mathrm{~nm}$.

that the spectral reflectance measured from the Sea-viewing Wide Field-of-view Sensor (SeaWiFS) in dusty conditions could be matched only by decreasing the imaginary part of mineral aerosol refractive index (see Table 4 of Moulin et al., 2001). These findings were confirmed through the study of Haywood et al. (2003) who analysed important episodes of dust transported between Dakar $\left(14.7^{\circ} \mathrm{N}, 17.3^{\circ} \mathrm{W}\right)$ and Sal Island $\left(16^{\circ} \mathrm{N}, 24^{\circ} \mathrm{W}\right)$. The refractive index is the source of a great part of the uncertainty in estimating Dust Radiative Effect (DRE), other sources of uncertainty include, by order of importance, the particle size distribution, the vertical distribution, cloud albedo and the albedo of the underlying surface (Liao and Seinfeld, 1998).

Tegen et al. (1996), Woodward (2001) and Myrhe and Stordal (2001) have estimated DRE in the shortwave. These estimates range from -0.61 to $-0.16 \mathrm{~W} \mathrm{~m}^{-2}$ and were all based upon refractive indices published by Patterson et al. (1977), Volz (1973), D’Almeida et al. (1991), Shettle and
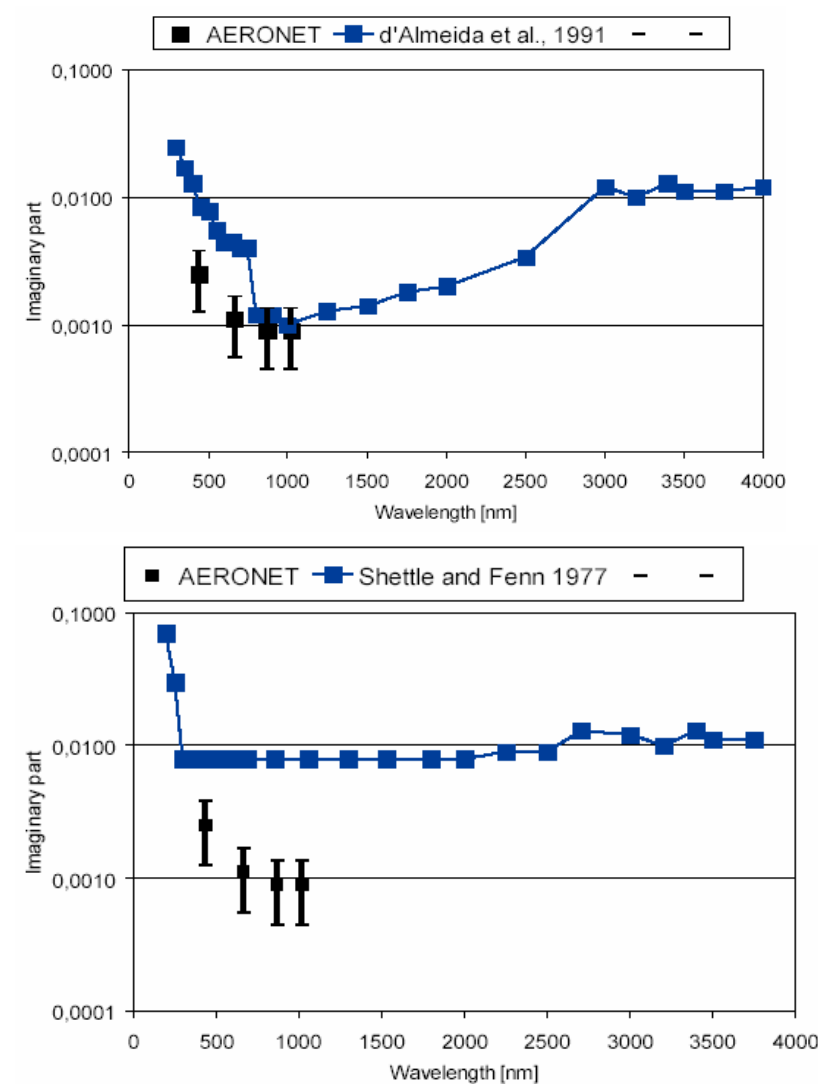

Fig. 2. Imaginary part of mineral aerosol refractive indices. The filled blue squares indicate measurements that were collected by d'Almeida et al. (1991) (top panel) and by Shetlle and Fenn (1979) (bottom panel). The filled black squares indicate the AERONET measurements reported by Dubovik et al. (2002). Uncertainties are as described for Fig. 1.

Fenn (1979) and Sokolik et al. (1993), see Fig. 1. The refractive indices used in these studies are 3 to 5 times greater than for the AERONET values as the wavelength increases from 440 to $1020 \mathrm{~nm}$ (see Figs. 1 and 2). Based on these reported imaginary part of the refractive index, Fig. 2 of Claquin et al. (1998), attempted to define minimum and maximum values over both shortwave and longwave spectra. The reported values over the spectral range 0.3 to $30 \mu \mathrm{m}$ span from a factor of five to an order of magnitude. Such large uncertainties in the refractive index do not put a constraint on whether dust absorption leads to a cooling or a warming of the atmospheric column over most surfaces.

As of today, coupled climate models and forecast models do not include the radiative effect of mineral aerosols due to these uncertainties and to the complexity to represent dust size distribution. Dust has been shown to affect weather forecast in tropical regions (Alpert et al., 1998; Perez et al., 2006). Hence, it is important to address the uncertainty in the radiative effect of mineral dust. This paper uses data that recently became available from the AERONET sunphotometer 
network, to re-evaluate the validity of earlier refractive indices and present some possible reasons for discrepancies between the refractive indices published.

Section 2 of this paper describes the General Circulation Model (GCM) coupled to a chemical/aerosol module used to derive the dust distribution. In Sect. 3, we compare AERONET retrieved refractive indices (Dubovik et al., 2002) to other published refractive indices. The fourth part follows a recommendation made in the conclusions of the 1st International workshop on Mineral Aerosols (Sokolik, 1999): we include the mineralogical composition of dust in a more realistic way in the model through the treatment of the principal components in terms of optical properties. We then compute the annual mean dust radiative forcing at the top of the atmosphere and at the surface by varying mineralogical composition for different assumptions based upon measured composition of internally mixed and externally mixed minerals. In Sect. 5, model-derived DRE is compared with sattelite-based measurements of clear sky shortwave radiative effect of mineral dust off-coast western Africa. Finally we discuss in Sect. 6 whether mineral dust is warming or cooling the atmospheric column, which was singled out as one of the great uncertainties of the radiative forcing by aerosols (Intergovernmental Panel on Climate Change (IPCC), 2001).

\section{Model and methods}

\subsection{LMDZ-INCA}

LMDz-INCA stands for a coupled General Circulation Model (LMDz) described by Hourdin et al. (2006) with a Chemistry-Aerosol module (INCA). The INCA (Interactions between Chemistry and Aerosols) module includes the treatment of gases important in the radiative budget $\left(\mathrm{CO}_{2}, \mathrm{CH}_{4}\right.$, CO, CFCs, and HCFCs, see Hauglustaine et al., 2004) as well as of the different aerosol components (sulphate, BC, organic, dust, and seasalts). In order to be computationally efficient and accurate, a modal scheme for particle size distribution has been adapted to treat an aerosol population. This allows to follow the size distribution of the aerosol with only two tracers per mode (one tracer follows the mass, and a second one follows the number distribution). Hence, it reduces the number of tracers by as much as an order of magnitude with a comparable precision in the computation (see Schulz et al., 1998). The drawback of the modal scheme is that the number of modes is set at the beginning of the run and it is difficult to add modes to the distribution. In addition, an implicit assumption is made that the processes such as deposition and chemical transformation do not affect the width of the size distribution but only its mass median diameter. The merits of this approach have been discussed for: an episode of dust transport across the Mediterranean Sea in Schulz et al. (1998), a comparison of dust optical depth to satellite data in Guelle et al. (2000), and an extensive comparison of sea-salts to measurements of size distribution in the coarse and fine modes in Guelle et al. (2001). The wet scavenging scheme distinguishes between stratiform and convective precipitation. Both types of precipitation are treated separately and parameterised as a first-order loss process (Giorgi and Chameides, 1985).

$d C_{g} / d t=-\beta C_{g}$

where $C_{g}$ is the aerosol concentration in the gas phase and $\beta$ the scavenging coefficient $\left(\mathrm{s}^{-1}\right)$. The rain liquid water content $(L)$ is derived from the total (solid + liquid) water flux calculated by the GCM. Rainout by snow occurs with the same efficiency as liquid water. The scavenging by convective precipitation is calculated as part of the upward convective mass flux based on a modified version of the scheme proposed by Balkanski et al. (1993). Based on this formulation and on the previous equation, we derive for the scavenging coefficient associated with convective precipitation:

$\beta^{c v}=-f F_{u} g / p$

where $f$ is the fraction of aerosol removed, $F_{u}$, the upward convective mass flux diagnosed by the GCM $\left(\mathrm{kg} \mathrm{m}^{-2} \mathrm{~s}^{-1}\right)$, and $g$, the gravity constant. We assume as in Liu et al. (2001) that for convective events, the fraction, $f$, of aerosol removed is:

$f=\left(1-e^{-\alpha \Delta z}\right)$

where $\Delta z[\mathrm{~m}]$ is the height in the convective tower calculated from the cloud base. The scavenging efficiency $\alpha$ $\left[\mathrm{m}^{-1}\right]$ is ratio of the rate constant for conversion of cloud water to precipitation $\left(C_{p r}\right)$ and the updraft velocity $w$. Based on Mari et al. (2000) and Liu et al. (2001), we adopt $C_{p r}=5 \times 10^{-3} \mathrm{~m} \mathrm{~s}^{-1}, \mathrm{w}=10 \mathrm{~m} \mathrm{~s}^{-1}$ leading $\alpha=5 \times 10^{-4} \mathrm{~m}^{-1}$.

\subsection{Treatment of the dust emissions}

Dust emissions in the model follow Schulz et al. (1998) and Guelle et al. (2000). The dust fluxes are calculated as a function of soil threshold velocities and wind friction velocities, which are in turn parameterized as a function of the soil particle size and the surface roughness length. Then the dust emission fluxes are determined according to the clay content of eroding soil. This formulation has shown to give very good agreement with measurements of dust mass concentrations and AODs in previous global modeling studies (Schulz et al., 1998; Guelle et al., 2000). To account for the high spatial variability in horizontal wind speeds, dust emission fluxes have been generated off line using ECMWF 6-hourly horizontal $10-\mathrm{m}$ wind speeds at a resolution of $1.125^{\circ} \times 1.125^{\circ}$ and are regridded to the model resolution of $3.75^{\circ} \times 2.5^{\circ}$. Dust emission is inhibited in the model when humidity persists over the upper soil layer following precipitation. Soil humidity is estimated through a simple bucket 
Table 1. Refractive indices of the different minerals constitutive of dust and references used.

\begin{tabular}{|c|c|c|}
\hline \multicolumn{2}{|c|}{ Infrared spectrum } & \multirow{2}{*}{$\frac{\text { wavelengths }}{1.6 \text { to } 36 \mu \mathrm{m}}$} \\
\hline Quartz & Peterson and Weinmar (1969) & \\
\hline & Steyer et al. (1974) & 7.14 to $24 \mu \mathrm{m}$ \\
\hline & Hunt et al. (1950) $\left(^{*}\right)$ & 1 to $16 \mu \mathrm{m}$ \\
\hline \multirow[t]{2}{*}{ Illite } & Querry (1987) & 0.2 to $32.8 \mu \mathrm{m}$ \\
\hline & Hunt et al. (1950) $\left(^{*}\right)$ & 2 to $16 \mu \mathrm{m}$ \\
\hline \multirow[t]{3}{*}{ Montmorillonite } & Querry (1987) & 0.2 to $32.8 \mu \mathrm{m}$ \\
\hline & Toon et al. (1977) & 5 to $40 \mu \mathrm{m}$ \\
\hline & Hunt et al. (1950) $\left(^{*}\right)$ & 2 to $16 \mu \mathrm{m}$ \\
\hline \multirow[t]{2}{*}{ Kaolinite } & Roush et al. (1991) & 5 to $25 \mu \mathrm{m}$ \\
\hline & Hunt et al. (1950) $\left(^{*}\right)$ & 2 to $16 \mu \mathrm{m}$ \\
\hline \multirow[t]{2}{*}{ Calcite } & Querry et al. (1978) & 0.2 to $32.8 \mu \mathrm{m}$ \\
\hline & Long et al. (1993) & 2.5 to $333 \mu \mathrm{m}$ \\
\hline \multirow[t]{2}{*}{ Hematite } & Popova et al. (1973) & 14.3 to $50 \mu \mathrm{m}$ \\
\hline & Hunt et al. (1950) $(*)$ & 2 to $16 \mu \mathrm{m}$ \\
\hline \multirow[t]{2}{*}{ Goethite } & Hunt et al. $(1950)(*)$ & 2 to $16 \mu \mathrm{m}$ \\
\hline & Visible spectrum & Wavelengths \\
\hline Quartz & Deer et al. $(1966)\left(^{+}\right)$ & 0.3 to $8.26 \mu \mathrm{m}$ \\
\hline \multirow[t]{2}{*}{ Montmorillonite } & Egan and Hilgeman (1979) & 0.185 to $0.4 \mu \mathrm{m}$ \\
\hline & Lindberg and Suyder (1972) & 0.3 to $2.1 \mu \mathrm{m}$ \\
\hline \multirow[t]{2}{*}{ Illite } & Egan and Hilgeman (1979) & 0.185 to $0.4 \mu \mathrm{m}$ \\
\hline & Lindberg and Snyder (1972) & 0.3 to $2.1 \mu \mathrm{m}$ \\
\hline \multirow[t]{2}{*}{ Kaolinite } & Egan and Hilgeman (1979) & 0.185 to $0.4 \mu \mathrm{m}$ \\
\hline & Lindberg and Smith (1974) & 0.4 to $2.4 \mu \mathrm{m}$ \\
\hline Calcite & Deer et al. $(1966)\left({ }^{+}\right)$ & 0.33 to $8.26 \mu \mathrm{m}$ \\
\hline Hematite & Bedidi and Cervelle (1993) & 0.4 to $0.7 \mu \mathrm{m}$ \\
\hline Goethite & Bedidi and Cervelle (1993) & 0.4 to $0.7 \mu \mathrm{m}$ \\
\hline
\end{tabular}

* indicates data that had to be extrapolated

+ indicates that a mean value was taken over the spectral interval considered

equation. We use a spectral description of the size distribution with a mass median diameter (MMD) of $2.5 \mu \mathrm{m}$ (modal diameter of $0.59 \mu \mathrm{m}$ ) at the source and a width $\sigma=2.0$ (see Schulz et al., 1998). We will see that a coarse mode with an MMD of $5.0 \mu \mathrm{m}$ (modal diameter of $1.18 \mu \mathrm{m}$ ) changes the optical depth in the source regions but has little effect over distant areas.

\subsection{Radiative code}

The radiative code in the LMDZ GCM consists of an improved version of the parameterizations of Fouquart and Bonnel (1980) (solar radiation) and Morcrette (1991) (terrestrial radiation). The shortwave spectrum is divided into two intervals: $0.25-0.68$ and $0.68-4.00 \mu \mathrm{m}$, respectively, and the longwave spectrum is divided into 5 intervals. The model accounts for the diurnal cycle of solar radiation and allows fractional cloudiness to form in a grid box. In the cloudfree portion of the grid box, the optical properties of aerosols are combined and a delta approximation of the forward scattering peak is made to account for the highly asymmetric aerosol phase function. The reflectivity and transmissivity of a layer are computed using the random overlap assumption (Morcrette and Fouquart, 1986) by averaging the clear and cloudy sky fluxes weighted linearly by their respective fractions in the layer. The radiative fluxes are computed every two hours, at the top-of-atmosphere and at the surface, with and without the presence of clouds, and with and without the presence of aerosols. The clear-sky and all-sky aerosol radiative forcings can then be estimated as the differences in radiative fluxes with and without aerosols.

\section{Dust refractive indices}

Works from Liao and Seinfeld (1998), Sokolik and Toon (1999) and from Claquin et al. (1999) have discussed the main sensitivities of the dust radiative perturbation to its mineralogical content and to the representation of the size distribution. Sokolik and Toon (1999) and Claquin et al. (1999) showed that dust mineralogy can be represented with six main minerals: illite, montmorillonite, kaolinite, quartz, calcite and hematite. Hematite accounts here for the two main forms of iron-oxides in this simplified mineralogy, i.e., 
Table 2. Percentage of the volume for the 6 different minerals used to compute the refractive index, density for each of the minerals is, respectively, $5.3,2.71,2.65,2.71$ and $2.71 \mathrm{~g} \mathrm{~cm}^{-3}$, for hematite, illite, quartz, calcite, kaolinite and montmorillonite.

\begin{tabular}{lccc}
\hline & $\begin{array}{c}\text { S1 } \\
\text { Central Hematite }\end{array}$ & $\begin{array}{c}\text { S1b } \\
\text { High Hematite }\end{array}$ & $\begin{array}{c}\text { S1c } \\
\text { Low Hematite }\end{array}$ \\
\hline Hematite & 1.5 & 2.7 & 0.9 \\
Illlite & 31.5 & 30.3 & 32.1 \\
Quartz & 14.0 & 14.0 & 14.0 \\
Calcite & 6.0 & 6.0 & 6.0 \\
Kaolinite & 24.0 & 24.0 & 24.0 \\
Montmorillonite & 23.0 & 23.0 & 23.0 \\
Total & 100.0 & 100.0 & 100.0 \\
\hline
\end{tabular}

hematite and goethite, which have comparable physical and optical properties. For each mineral the real and imaginary part have been defined spectrally and we indicate in Table 1 the refractive indices that are used in this study (see also Table 3 Sokolik and Toon, 1999). We use the mineralogical database described by Claquin et al. (1999) to derive the absorption of mineral dust with hematite contents characteristic of arid and semi-arid regions.

Absorption by mineral dust in the shortwave is mostly due to the presence of iron oxides in the form of hematite. The mineralogical database over arid and semi-arid areas allows searching for the fraction of hematite in mineral dust relative to the other minerals present. $1 \%, 5 \%, 50 \%, 95 \%$ and $99 \%$ of the areas of the database have a volume weighted hematite of more than 3.4, 2.7, 1.5, 0.9 and $0.8 \%$, respectively. The intent of this paper is to link the radiative effect of dust to its hematite content. Hence, the sensitivity studies that are presented refer to constant hematite content. Estimates of iron oxides in dust samples by Lafon et al. (2004) and Linke et al. (2006) give credence to these amounts since the ranges for iron oxides from the samples they analyzed are respectively: 1.4 to $2.8 \%$ and 1.0 to $2.5 \%$ in volume. In the simulations discussed in this paper, the amount of hematite of a given model run is kept constant. We will note $\mathrm{S} 1$ the reference run which refers to an internally mixed dust with a hematite content of $1.5 \%$ in volume (equivalent to $3.0 \%$ by weight). Two additional simulations were conducted to study the sensitivity to the hematite fraction; they are noted S1b and S1c for respectively $0.9 \%$ and $2.7 \%$. To adjust the volume of the other minerals we only vary the illite content (Table 2). We checked that varying other mineral contents, (i.e., of quartz, calcite, illite and montlorillonite keeping hematite constant), led to insignificant variations in refractive indices compared to hematite (not shown). The simulation S2 uses the refractive index reported by Patterson et al. (1977) and by Volz (1973). It allows linking this work with previous published work on the radiative effect of dust (Table 3). In simulation S2, we constructed the refractive indices in the range 700 to
Table 3. Refractive indices used to estimate dust radiative effect.

\begin{tabular}{lc}
\hline Studies & Refractive indices used \\
\hline Tegen et al. (1996) & Patterson-Volz \\
Simulation S2 (this study) & Patterson-Volz \\
Woodward (2001) & From a range of measurements* \\
Myhre and Stordal (2001) & d'Almeida et al. (1991) \\
Perez et al. (2006) & Koepke et al. (1997)** \\
Simulations S1, S3, S4 (this study) & $1.5 \%$ hematite internally mixed \\
\hline
\end{tabular}

* references: Carlson and Benjamin (1980), Sokolik et al. (1993, 1998), WMO (1993). ** The refractive indices from the GADS database are partly based upon the work of Shettle and Fenn (1979) and d'Almeida et al. (1991).

$2500 \mathrm{~nm}$ by interpolating linearly between the values of Patterson et al. (1977) and Volz (1973).

\subsection{Dielectric model for mixes minerals}

Atmospheric dust sample show that dust particles are mostly found in the form of aggregates (Reid et al., 2003). The ironrich fraction of the dust which includes hematite is generally embedded in a matrix made of clay (Reid et al., 2003). Therefore, an optical model is needed to derive the refractive index of these minerals as an internal mixture. If we assume a mixture of two minerals composed of a matrix within which a second mineral is embedded as spherules, the MaxwellGarnet approximation allows to compute an effective dielectric constant for the mineral aggregate. The dielectric constant of the aggregate, $\epsilon_{\mathrm{agg}}$, a function of the dielectric constants of the matrix, $\epsilon_{m}$, and of the inclusion, $\epsilon$ :

$\epsilon_{\mathrm{agg}}=\epsilon_{m}\left\{\left(1+\left[\frac{3 v\left(\epsilon-\epsilon_{m}\right)}{\epsilon+2 \epsilon_{m}}\right]\right)\left(1-\frac{v\left(\epsilon-\epsilon_{m}\right)}{\epsilon+2 \epsilon_{m}}\right)^{-1}\right\}$

The refractive index of the mixed aerosol, $n_{\text {agg }}$ is then obtained from $\epsilon_{\text {agg }}$ as:

$n_{\mathrm{agg}}=\left(\epsilon_{\mathrm{agg}}\right)^{1 / 2}$

where $n_{\text {agg }}$ is the complex refractive index of the matrix, $v$ is the ratio of the volume of the inclusion to the total volume, and $n=(\text { epsilon })^{1 / 2}$ is the complex refractive index of the inclusion.

\subsection{Refractive index of internally mixed minerals}

A straightforward comparison of dust refractive indices reported by Patterson et al. (1977) and by Volz (1973) to AERONET measurements (Fig. 1) indicates that models have overestimated mineral dust absorption. Over the spectral region documented by Patterson and al. (1977) (i.e. between 300 and $700 \mathrm{~nm}$ ) the imaginary part of the refractive index is one order of magnitude greater than the value retrieved from AERONET measurements. When we take the 

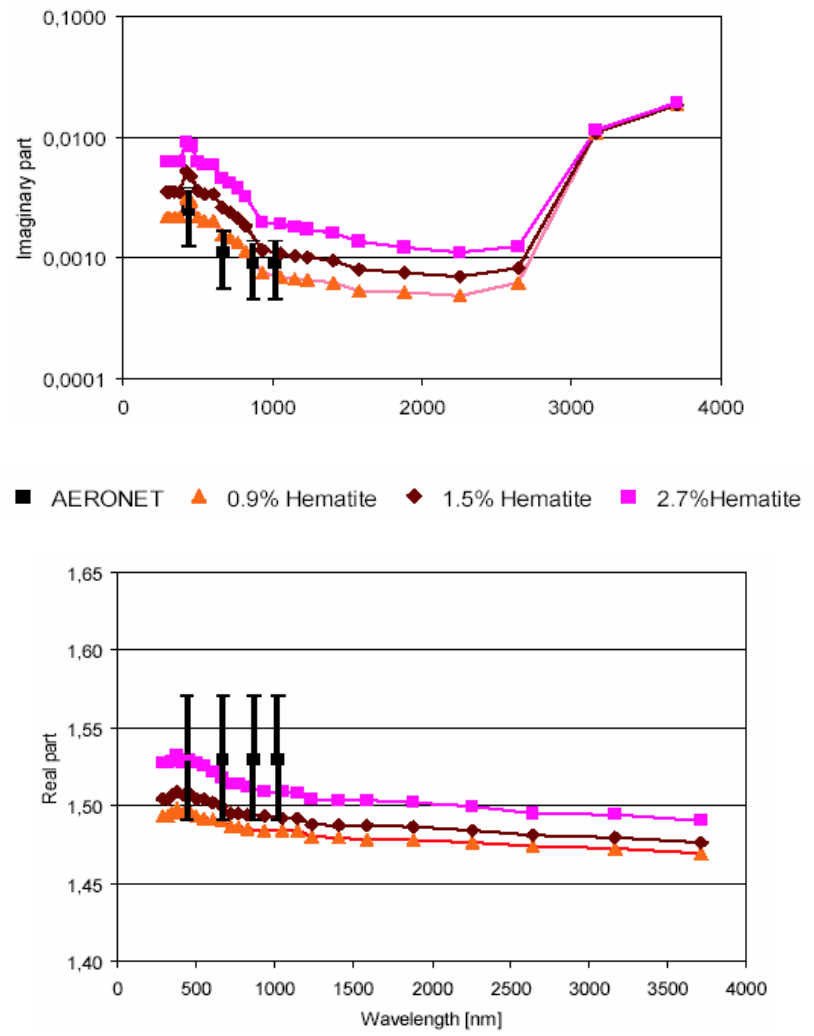

Fig. 3. Real and imaginary parts of mineral aerosol refractive indices. The solid triangles and squares are for an internal mixture with respectively $0.9,1.5$ and $2.7 \%$ hematite by volume and the refractive indices have been computed with the dielectric model (see text). The AERONET measurements are the ones reported by Dubovik (2002). Uncertainties are 0.04 on the real part of the refractive index and $50 \%$ on the imaginary part (Dubovik, 2002, and personal communication).

upper end of the uncertainty range in the AERONET measurements, Patterson et al. (1977) values are still a factor 5 to 9 larger over this same spectral range. The consistency of the values of refractive indices retrieved from AERONET over all sites where mineral dust is the dominant aerosol component suggests that the absorption of airborne mineral dust is lower than the values of Patterson et al. (1977) and by Volz (1973). We also compared these values with two other sets of mineral dust refractive indices that have been used in modelling work. The first one is the refractive indices reported by d'Almeida et al. (1991) that are part of the Global Aerosol Climatology where the spectral range for mineral aerosol refractive index spans from 300 to $4000 \mathrm{~nm}$. These measurements show similar discrepancies at the two wavelengths 440 and $670 \mathrm{~nm}$, whereas the comparison with the AERONET shows a much better agreement at 870 and $1020 \mathrm{~nm}$ (Top panel, Fig. 2). In a different set of measurements of Shettle and Fenn (1979), the imaginary part of the refractive index is overestimated by a factor 4 to 10 for the 4 wavelengths re-
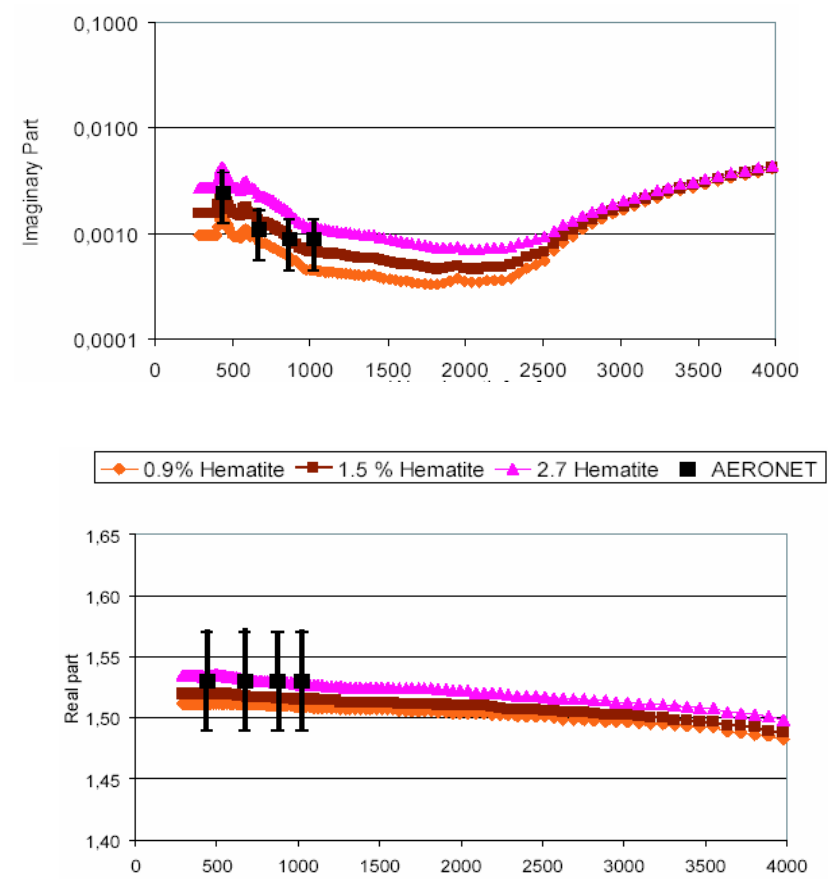

Fig. 4. Real and imaginary parts of mineral aerosol refractive indices. The solid triangles and squares are for an internal mixture with respectively $0.9 \%, 1.5$ and $2.7 \%$ hematite by volume and the refractive indices have been computed for hematite coating the other 5 other minerals (calcite, quartz, illite, kaolinite and montmorillonite). These refractive indices correspond respectively to the cases $\mathrm{S} 1 \mathrm{~b}, \mathrm{~S} 1$ and S1c. The AERONET measurements are the ones reported by Dubovik (2002). Uncertainties are 0.04 on the real part of the refractive index and 50\% on the imaginary part (Dubovik, 2002, and personal communication).

ported when compared with AERONET measurements (Bottom panel, Fig. 2).

Figures 3 and 4 show the refractive indices of dust for 2 hypotheses of mixing: one for a volume weighed average aggregate of minerals (Fig. 3) and the second one for hematite imbedded in a matrix made of quartz, calcite, illite, kaolinite or montmorillonite (Fig. 4). Table 1 indicates the references that were used in this work for the refractive indices of the individual minerals. When minerals are treated as a volume weighted average, the imaginary part of the refractive index is within or close to the range of uncertainty indicated in AERONET measurements at the 4 wavelengths. In contrast, for the high hematite content $(2.7 \%$ by volume), this imaginary part is just as large as in the case of the Patterson et al. (1977) measurements or of d'Almeida et al. (1991) at wavelengths 440 and $670 \mathrm{~nm}$.

When minerals are considered as an internal mixture of minerals with embedded hematite, at all 4 AERONET wavelengths $(440,670,870$ and $1020 \mathrm{~nm})$ the mixture with low hematite content $(0.9 \%)$ and the mixture with high hematite content $(2.7 \%)$ bracket the imaginary values reported by 

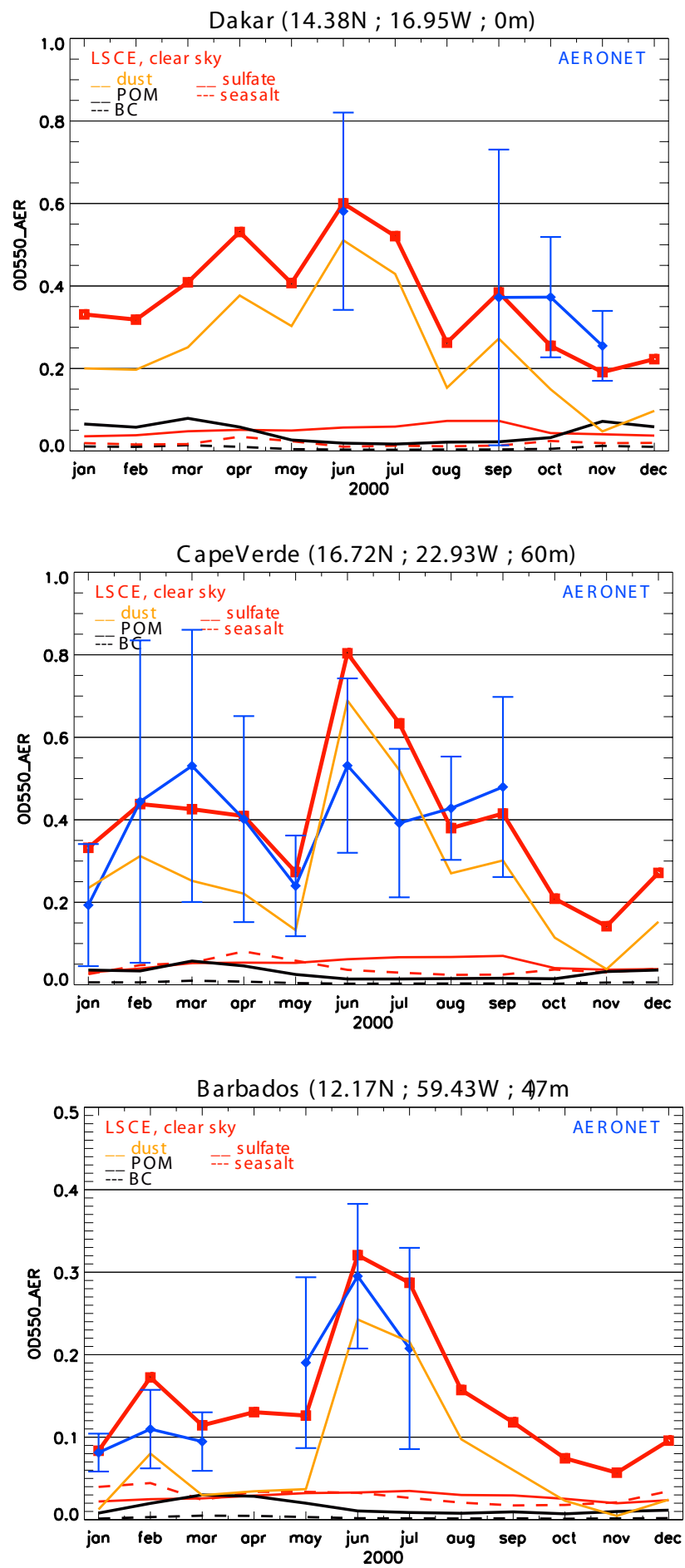

Fig. 5. Comparison of simulated optical depth at $550 \mathrm{~nm}$ to AERONET retrieved ones for 3 stations over Africa and across the tropical Atlantic in blue. The solid lines are yellow for dust and red for sulphate. The dashed lines represent the simulated OD for black carbon. There are black for carbon and red for seasalt.

Dubovik et al. (2002). Not only does the imaginary part of the refractive index agree well with the ranges measured in
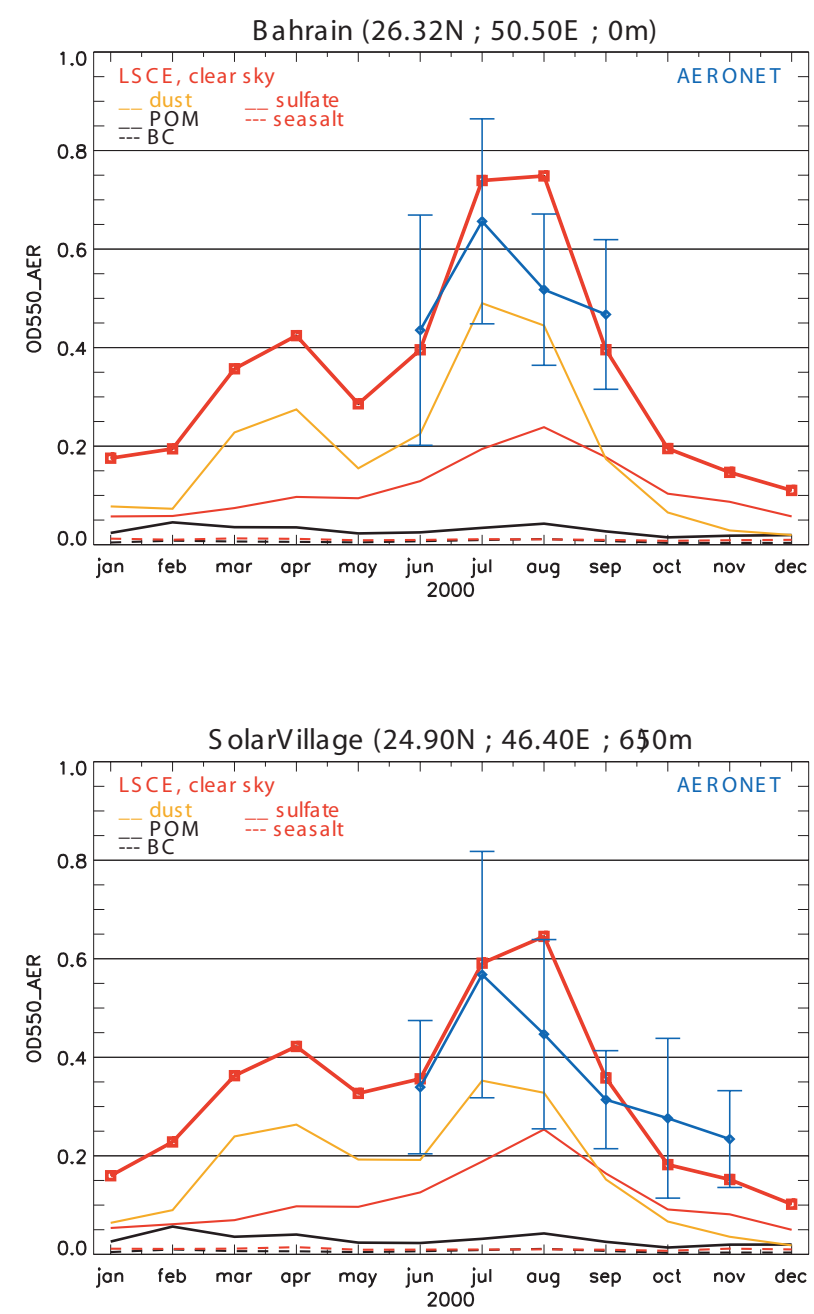

Fig. 6. Comparison of simulated optical depth at $550 \mathrm{~nm}$ to AERONET retrieved ones for 2 stations on the Arabian Peninsula in blue. The solid lines are yellow for dust and red for sulphate. The dashed lines represent the simulated OD for black carbon. There are black for carbon and red for seasalt.

AERONET but the constraint set by the real part is also satisfied. The central value of $1.5 \%$ hematite is in very good agreement with these measurements (see Fig. 4). For the longwave, the refractive indices were compared with Sokolik et al. (1999). We checked that no large difference in refractive indices was found over in these spectral intervals. The discussion in this paper is primarily focused on the shortwave spectrum.

The approach based upon mineralogy, that was first proposed by Sokolik et al. (1999), helps us reconcile the derived refractive indices with the measured ones. 

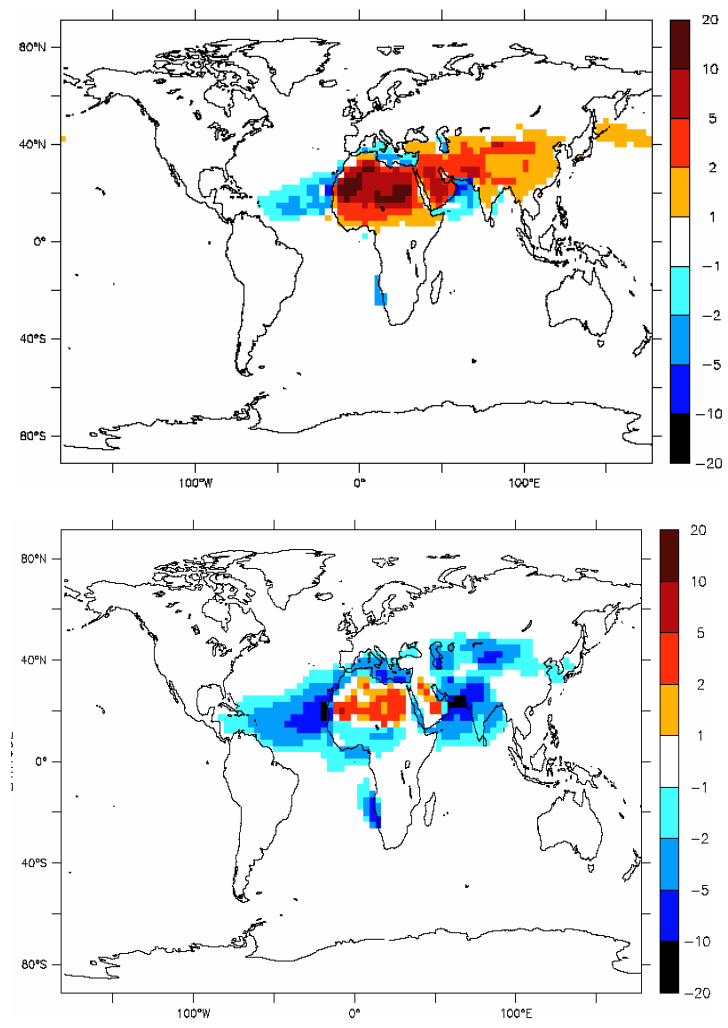

Fig. 7. Comparison of TOA radiative forcing of dust for 2 different hypotheses for dust refractive index: Top panel: Patterson and Volz; Bottom Panel: $1.5 \%$ by volume hematite content internally mixed.

\section{Modelled direct radiative forcing of mineral dust}

\subsection{Comparison of modelled optical depths with AERONET}

We present in Figs. 5 and 6 the comparison of AERONET retrieved optical depths to the simulated ones at 5 sites, 3 over Africa and the tropical Atlantic (Dakar, Cape Verde and Barbados) and 2 sites over the Arabian Peninsula (Bahrain and Solar Village). These sites were chosen for their position along the main pathway of dust transport. Three of these sites (Cape Verde, Bahrain and Solar Village) were chosen by Dubovik et al. (2002) to retrieve the refractive indices since they are mostly influenced by dust. As can be seen from these figures the seasonality is well reproduced at all sites and the amplitude of the optical depth agrees well with these observations. Figures 5 and 6 indicate that the modelled dust captures well the seasonal variations and the loads of dust aerosols over these regions.

\subsection{Influence of the different sets of refractive indices}

We present in Fig. 7 the top of atmosphere (TOA) aerosol radiative forcing of dust for two cases of refractive indices: $S 1$ in which hematite is internally mixed as $1.5 \%$ of the total volume, S2, a simulation with the refractive index of dust from Patterson et al. (1977) and Volz (1973). The refractive index from $S 1$ is in very good agreement with the AERONET retrieved indices at the 4 wavelengths (Fig. 4). For these two cases, the effect of mineral dust absorption is dramatically different over both continents and oceans (Fig. 7). Over continents, the sign of the forcing depends mainly surface albedo. When the yearly averaged surface albedo reaches values greater than 0.2 , the shortwave radiative forcing turns positive. The presence of low level clouds over surface albedos between 0 and 0.2 will lead to a positive TOA forcing if clouds are present below the aerosol layer throughout the year. Table 4 summarizes the resulting forcing which averages the positive and negative contributions over oceanic and continental regions. Over arid and semi-arid areas such as the Sahara and the Arabian Peninsula, dust radiative forcing is much more positive in the hypothesis of the $S 2$ simulation compared with $S 1$. The more dramatic differences occur for 3 continental regions the Sahel, the Arabian Peninsula and Asia where the sign of the TOA forcing is negative for the simulation $S 1$ and positive for $S 2$. Over the tropical Atlantic, and North Indian Ocean both TOA and surface radiative forcing from dust have negative signs in $S 1$ and $S 2$ cases. The atmospheric heating is 3 to 4 times smaller in the $S 1$ than in the $S 2$ simulation over these regions. Over the Sahara region, the TOA forcing from mineral dust changes is positive for both cases. The heating over the Saharan region is also 4 times smaller in $S 1$ compared to the $S 2$ case (Table 4).

\subsection{Shortwave versus Longwave TOA radiative forcing}

Figure 8 presents respectively the shortwave (top panel) and longwave (middle panel) contribution to the TOA forcing for simulation $S 1$ case. Globally averaged, the shortwave and longwave TOA forcings amount respectively to -0.68 and $+0.29 \mathrm{Wm}^{-2}$, the overall forcing is $-0.39 \mathrm{Wm}^{-2}$. Top of the atmosphere shortwave forcing is always negative over dark surfaces such as the oceans in agreement with findings of Liao and Seinfeld (2001, Figs. 1 and 2) when clouds are not permanently present. The bottom panel of Fig. 8 presents the yearly average TOA forcing from dust (SW+LW). Over bare surfaces the forcing is positive and can reach +2 to $+5 \mathrm{Wm}^{-2}$ over source regions in Sahara or over the Arabian Peninsula. In contrast, regions with the strongest negative forcing are the Eastern tropical Atlantic and the Northern Indian Ocean, large regions over which the yearly mean minimum forcing is between -5 to $-20 \mathrm{~W} \mathrm{~m}^{-2}$.

In order to evaluate the DRE when the refractive indices of Patterson-Volz are used, we ran the model with the same size distribution clouds and scavenging scheme and computed the direct radiative effect for case $S 2$ (see Table 5). The TOA forcing computed turns also positive with a value of $+0.35 \mathrm{Wm}^{-2}$ globally and which consists of an overall positive SW TOA $\left(+0.05 \mathrm{Wm}^{-2}\right)$ forcing combined with a $\mathrm{LW}$ TOA forcing of $+0.30 \mathrm{Wm}^{-2}$ as summarized in Table 5 . 
Table 4. Annual mean Mineral Dust Forcing (SW+LW) over different regions.

\begin{tabular}{|c|c|c|}
\hline Region & $\begin{array}{l}\text { Case } \mathrm{S} 1 \\
\left(\mathrm{~W} \mathrm{~m}^{-2}\right)\end{array}$ & $\begin{array}{l}\text { Case } \mathrm{S} 2 \\
\left(\mathrm{~W} \mathrm{~m}^{-2}\right)\end{array}$ \\
\hline Tropical Atlantic & $\mathrm{TOA}=-6.1$ & $\mathrm{TOA}=-2.1$ \\
\hline \multirow[t]{2}{*}{$\left(14^{\circ} \mathrm{N}-24^{\circ} \mathrm{N} ; 45^{\circ} \mathrm{W}-15^{\circ} \mathrm{W}\right)$} & $\mathrm{SRF}=-9.0$ & $S R F=-12.4$ \\
\hline & Heat $*=-6.1-(-9.0)=+2.9$ & Heat $=+10.3$ \\
\hline Sahara & $\mathrm{TOA}=+2.0$ & $\mathrm{TOA}=+9.3$ \\
\hline \multirow[t]{2}{*}{$\left(14^{\circ} \mathrm{N}-29^{\circ} \mathrm{N} ; 10^{\circ} \mathrm{W}-32^{\circ} \mathrm{E}\right)$} & $\mathrm{SRF}=-2.3$ & $\mathrm{SRF}=-6.4$ \\
\hline & Heat $=+4.3$ & Heat $=+15.7$ \\
\hline Sahel & $\mathrm{TOA}=-1.6$ & $\mathrm{TOA}=+2.2$ \\
\hline \multirow{2}{*}{$\left(6^{\circ} \mathrm{N}-14^{\circ} \mathrm{N} ; 10^{\circ} \mathrm{W}-32^{\circ} \mathrm{E}\right)$} & $\mathrm{SRF}=-3.7$ & $S R F=-6.4$ \\
\hline & Heat $=+2.1$ & Heat $=+8.6$ \\
\hline \multirow{3}{*}{$\begin{array}{l}\text { Arabian Peninsula } \\
\left(14^{\circ} \mathrm{N}-31^{\circ} \mathrm{N} ; 32^{\circ} \mathrm{E}-58^{\circ} \mathrm{E}\right)\end{array}$} & $\mathrm{TOA}=-0.7$ & $\mathrm{TOA}=+3.4$ \\
\hline & $S R F=-3.6$ & $S R F=-6.3$ \\
\hline & Heat $=+2.9$ & Heat $=+9.7$ \\
\hline \multirow{3}{*}{$\begin{array}{l}\text { Northern Indian Ocean } \\
\left(1^{\circ} \mathrm{N}-21^{\circ} \mathrm{N} ; 55^{\circ} \mathrm{E}-73^{\circ} \mathrm{E}\right)\end{array}$} & $\mathrm{TOA}=-2.9$ & $\mathrm{TOA}=-0.9$ \\
\hline & $\mathrm{SRF}=-4.4$ & $\mathrm{SRF}=-6.2$ \\
\hline & Heat $=+1.5$ & Heat $=+5.3$ \\
\hline \multirow{3}{*}{$\begin{array}{l}\text { Asia } \\
\left(24^{\circ} \mathrm{N}-51^{\circ} \mathrm{N} ; 69^{\circ} \mathrm{E}-141^{\circ} \mathrm{E}\right)\end{array}$} & $\mathrm{TOA}=-1.6$ & $\mathrm{TOA}=+1.3$ \\
\hline & $\mathrm{SRF}=-4.0$ & $S R F=-6.1$ \\
\hline & Heat $=+2.4$ & Heat $=+4.8$ \\
\hline
\end{tabular}

* The column heating $\left(\mathrm{W} \mathrm{m}^{-2}\right)$ is computed as the difference between TOA and surface fluxes.

Table 5. Top of atmosphere (TOA) and surface (SRF) dust radiative effect $\left(\mathrm{W} \mathrm{m}^{-2}\right)$.

\begin{tabular}{lccccccc}
\hline Case & $\begin{array}{c}\text { Load }\left(\mathrm{mg} \mathrm{m}^{-2}\right) \\
0<\mathrm{D}<1 \mu \mathrm{m}\end{array}$ & $\begin{array}{c}\text { Load } \\
1<\mathrm{D}<10 \mu \mathrm{m}\end{array}$ & Total OD & SW TOA & LW TOA & SW+LW TOA & SW+LW SRF \\
\hline S1 simulation (this study) & 4.0 & 36.2 & 0.031 & -0.68 & +0.29 & -0.39 & -0.92 \\
\hline $\begin{array}{l}\text { S2 simulation (this study) } \\
\text { this study) }\end{array}$ & 4.0 & 36.2 & 0.031 & +0.05 & +0.30 & +0.35 & -1.44 \\
$\begin{array}{l}\text { Tegen et al. (1996) } \\
\text { Woodward (2001) }\end{array}$ & 14.7 & 21.6 & 0.026 & -0.39 & +0.53 & +0.14 & -1.92 \\
\hline Myhre and Stordal (2001) & 14.7 & NA & NA & -0.16 & +0.23 & +0.07 & -0.82 \\
\hline
\end{tabular}

* references for these measurements: Carlson and Benjamin (1980), Sokolik et al. (1993, 1998), WMO (1993)

\subsection{Comparison with other model results}

We now compare the values of DRE reported by Tegen et al. (1996), Woodward (2001) and Myrhe and Stordal (2001) with the $S 2$ simulation (Table 5). In all these studies the refractive indices used over the spectral intervals 300-700 nm and $2500-4000 \mathrm{~nm}$ have values close to the $S 2$ simulation. Woodward (2001) tried to create representative values, by taking the average of the extremes of a range of measurements at each wavelength from the compilation of measurements from Carlson and Benjamin (1980), Sokolik et al. (1993, 1998), WMO (1993). This leads to an imaginary part of the refractive index which is 3 to 5 times greater than for the AERONET values as the wavelength increases from
440 to $1020 \mathrm{~nm}$. The TOA radiative effect from dust aerosols in the shortwave was reported to be: $-0.39 \mathrm{Wm}^{-2}$ in Tegen et al. (1996), $-0.61 \mathrm{Wm}^{-2}$ with the same aerosol distribution by Myrhe and Stordal (2001), $-0.16 \mathrm{Wm}^{-2}$ in the work of Woodward (2001). We can only point out to the different possibilities that could account for these differences: differences in the refractive indices in the remaining window from 700 to $2500 \mathrm{~nm}$, different heights for the mineral dust distribution and differences in the radiative code or in water clouds. Clearly, it would be worthwhile focusing on the source of these differences but this is beyond the scope of this paper. 
Table 6. Sensitivity study to MMD, mineral dust radiative forcing $\left(\mathrm{W} \mathrm{m}^{-2}\right)$ at Top of the Atmosphere and at the surface.

\begin{tabular}{lcccc}
\hline Case & SW & LW & SW+LW TOA & SW+LW SRF \\
\hline \multicolumn{5}{c}{ Internal mixtures (this study) } \\
\hline S1: 1.5\% hematite & -0.68 & +0.29 & -0.39 & -0.92 \\
S1b: 0.9\% hematite & -0.76 & +0.29 & -0.47 & -0.81 \\
S1c: $2.7 \%$ hematite & -0.53 & +0.29 & -0.24 & -1.11 \\
\hline \multicolumn{5}{c}{ External mixtures (this study) } \\
\hline S3: 1.5\% hematite & -0.38 & +0.32 & -0.06 & -1.01 \\
S3b: 0.9\% hematite & -0.53 & +0.32 & -0.21 & -0.80 \\
S3c: $2.7 \%$ hematite & -0.15 & +0.32 & +0.17 & -1.33 \\
\hline \multicolumn{5}{c}{ External mixtures (Myrhe and Stordal, 2001) } \\
\hline 0.5\% hematite & -1.14 & +0.42 & -0.72 & NA \\
1.0\% hematite & -1.08 & +0.41 & -0.66 & NA \\
\hline \multicolumn{7}{c}{ Sensitivity study with 2 modes (this study) } \\
1st mode with MMD=2.5 $\mu$ m for and 2nd mode MMD=5.0 $\mu$ m at the source \\
\hline S4: 1.5\% hematite & -0.78 & +0.38 & -0.40 & -1.13 \\
\hline
\end{tabular}

4.5 Variation of the forcing with the hematite content in dust

We also studied the influence of the amount of hematite on the radiative forcing for the 3 hematite contents representative of low, central and high abundances of iron oxides in dust. The main differences in the radiative forcing at the top of the atmosphere can be seen over land for the two extremes cases $S 1 b$ and $S 1 c$ of low and high hematite (Fig. 9). The main areas where the hematite content changes the magnitude of the TOA forcing are over the 2 of the main source regions, the Sahara and the Arabian Peninsula. For the $S 1 b$ case (Table 6 ), this forcing remains in the range between 0 and $+2 \mathrm{Wm}^{-2}$. It approximately doubles over these regions when the hematite content corresponds to the more absorbing aerosol $S 1 c$ and averages between +2 and $+5 \mathrm{Wm}^{-2}$. The global annually averaged radiative forcing at the top of the atmosphere is presented for the 3 cases in Table 6 and the values lie between -0.47 and $-0.24 \mathrm{Wm}^{-2}$. The surface radiative forcing varies over a narrower range between -1.11 and $-0.81 \mathrm{Wm}^{-2}$. These results show the sensitivity of the dust radiative forcing to the hematite content.

\subsection{External mixing}

The process of saltation which is the bombardment of mineral aerosol aggregates at the surface is the prelude to their injection in the atmospheric boundary layer. Following saltation, the minerals transported in the atmosphere can be either in the form of external or internal mixtures. In the case of an external mixture, the different minerals can be treated in- dependently and assuming that the size distribution has been characterized. Using Mie theory assumes a spherical shape for particles which can introduce uncertainties of up to $15 \%$ (Mishchenko et al., 1997). Although we have shown by comparison with the AERONET retrieved refractive indices that the internally mixed case for minerals represents better the observed mineral dust optical properties, it is instructive to discuss the forcings as we treat dust as internally versus externally mixed minerals. The main differences in the TOA forcing occur for an external mixture of minerals with high hematite content (see Table 6, case $S 3 c$ ). Over most of the continental regions where dust is abundant; the TOA forcing exceeds $1 \mathrm{Wm}^{-2}$ and reaches $10 \mathrm{Wm}^{-2}$ over Western Sahara (not shown). These large positive forcings over continental areas with high dust loads lead to a global mean TOA forcing of $+0.17 \mathrm{Wm}^{-2}$ (Table 6 ). We rule out the possibility of an external mixture with high hematite based upon the refractive index computed for such an assembly of minerals. Such case would imply an imaginary part of the refractive index that exceeds AERONET retrievals by as much as an order of magnitude for certain wavelengths. In the case of an internal mixture with a hematite core, the top-of-atmosphere forcing rarely exceeds $5 \mathrm{Wm}^{-2}$ over Sahara and the TOA global average is $-0.24 \mathrm{Wm}^{-2}$.

In the case of the lower hematite contents (respectively 0.5 and $1.0 \%$ ) reported by Myrhe and Stordal (2001) in Table 6, the net flux at the top of the atmosphere is smaller than for case $S 1$ as one would expect since these aerosols have a lower hematite content and are therefore less absorbing. 

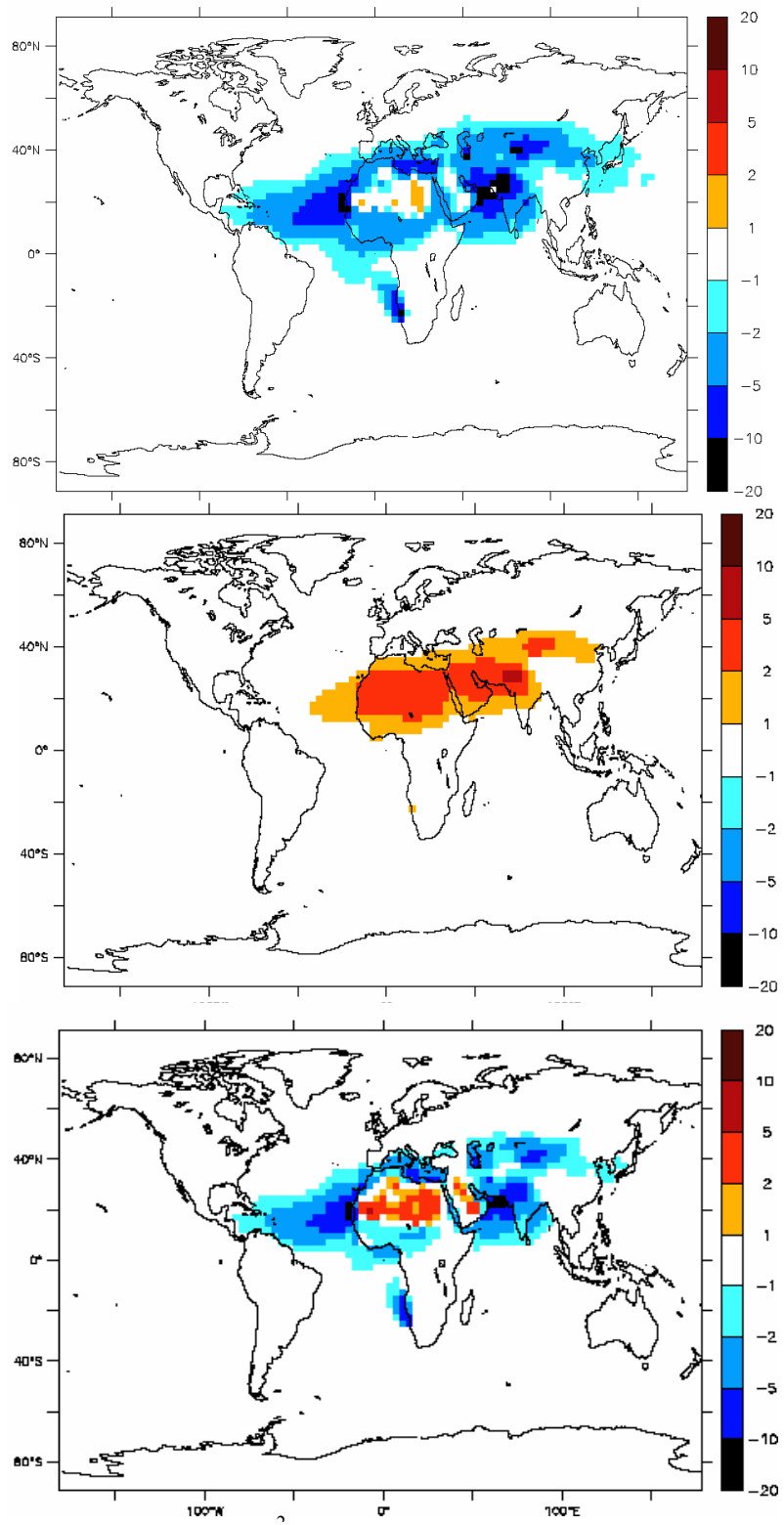

Fig. 8. TOA radiative forcing $\left(\mathrm{Wm}^{-2}\right)$ of mineral dust, the hematite represents $1.5 \%$ (by volume) of the minerals and the minerals are internally mixed. The Top, middle and bottom panels represent respectively the SW, LW, and the sum of SW+LW.

\subsection{Sensitivity of the forcing to the dust size distribution}

To investigate the sensitivity of this forcing to the variation in size distribution we vary in case $S 4$ the size spectrum of the dust in our 3-D INCA model. We added to the standard case with one mode (MMD $=2.5 \mu \mathrm{m}$ equivalent to a modal diameter of $0.59 \mu \mathrm{m}$ with a width $\sigma=2.0$ ), a coarse mode with an MMD of $5.0 \mu \mathrm{m}$ (modal diameter of $1.18 \mu \mathrm{m}$ and $\sigma=2.0$ ) at the point of injection. The yearly amount of dust injected in this simulation is twice the amount of dust injected in simulation S1. The coarse aerosol mode treated alone is unable
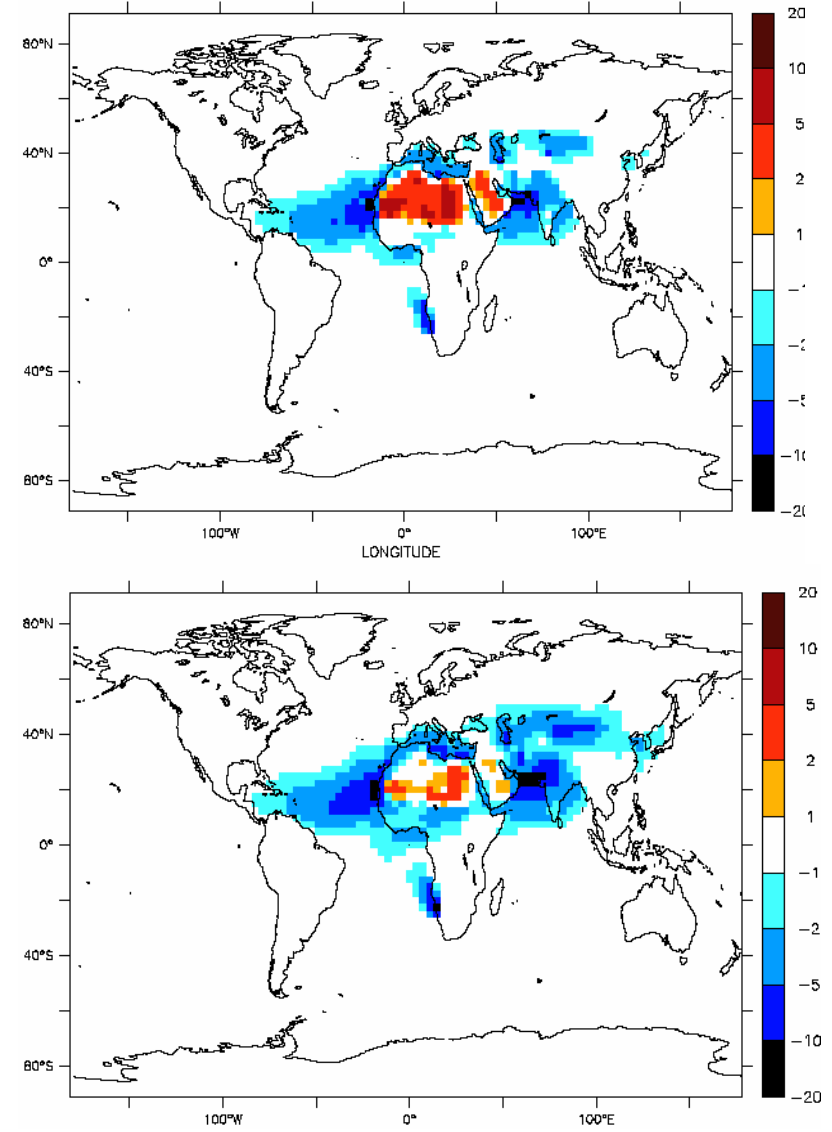

Fig. 9. TOA radiative forcing $\left(\mathrm{Wm}^{-2}\right)$ from mineral dust $(\mathrm{SW}+\mathrm{LW})$, the hematite is internally mixed and the top and bottom panels are for respectively 0.9 and $2.7 \%$ hematite (volume content).

to capture the observed optical depth across the equatorial Atlantic whereas when both a coarse and a fine mode the optical depth is well represented (not shown). The coarse mode alone has an optical depth that vanishes due to sedimentation as soon as dust is transported beyond the West Coast of Africa. Hence, the coarse mode alone with the narrow distribution we are studying here cannot by itself explain the optical depths seen by captors such as MODIS across the tropical Atlantic Ocean. The resulting forcing at the top of the atmosphere reaches then $-0.40 \mathrm{Wm}^{-2}$ (Table 6), a value very close to the standard simulation with a smaller aerosol mode as the decrease in the shortwave forcing is compensated by a significant increased in the longwave. With this additional coarse mode, the radiative forcing at the surface decreases by $23 \%$ (from -0.92 to $-1.13 \mathrm{Wm}^{-2}$ ).

\section{Comparison of mineral dust clear-sky forcing effi- ciency with measurements in the tropical Atlantic}

The broadband shortwave direct radiative effect from dust has been inferred using the synergy of different satellite and 
Table 7. Clear-Sky Mineral Dust Radiative Efficiency $\left(\mathrm{Wm}^{-2} \tau^{-} 1\right)$ Broadband Shortwave only. All values are averaged diurnally.

\begin{tabular}{lcccc}
\hline & TOA & Surface & $\begin{array}{c}\text { Ratio } \\
\text { [SRF/TOA }]\end{array}$ & Heating* \\
\hline \multicolumn{1}{c}{ Summer (JJA) over the Tropical Atlantic $\left(15^{\circ} \mathrm{N}-25^{\circ} \mathrm{N} ; 45^{\circ} \mathrm{W}-15^{\circ} \mathrm{W}\right)$} \\
\hline Li et al. (2004) & $-35 \pm 3$ & $-65 \pm 3$ & 1.9 & $+30 \pm 4$ \\
S1b: 0.9\% Hematite & -49 & -65 & 1.3 & +16 \\
S1: 1.5\% Hematite & -47 & -69 & 1.5 & +22 \\
S1c: 2.7\% Hematite & -45 & -76 & 1.7 & +32 \\
S2: Patterson-Volz & -29 & -88 & 3.0 & +60 \\
\hline 30 Sep 2000 near Dakar $(15 \mathrm{~N}, 17 \mathrm{~W})$ values reported in Anderson et al. $(2005)$ \\
The model gridbox averages over $\left(16.85^{\circ} \mathrm{W}-13.1^{\circ} \mathrm{W}\right.$ and $\left.13.75^{\circ} \mathrm{N}-16.25^{\circ} \mathrm{N}\right)$ \\
\hline Haywood et al. (2003) & -24 & -38 & 1.6 & +12 \\
S1b: 0.9\% Hematite & -24 & -48 & 2.0 & +24 \\
S1: $1.5 \%$ Hematite & -21 & -51 & 2.4 & +30 \\
S1c: $2.7 \%$ Hematite & -16 & -57 & 3.6 & +41 \\
S2: Patterson-Volz & +4 & -70 & -17.5 & +74 \\
\hline
\end{tabular}

* The column heating $\left(\mathrm{W} \mathrm{m}^{-2}\right)$ is computed as the difference between TOA and surface fluxes.

assumptions on the refractive indices and the size distribution of the dust aerosols. Li et al. (2004) using the synergy of the data from CERES (Clouds and Earth Radiant Energy System) and from MODIS (Moderate Resolution Imaging Spectroradiometer) were able to determine the aerosol clearsky forcing efficiency for two seasons: summer and winter. These measurements took place over the tropical Atlantic region $\left(45^{\circ} \mathrm{W}-15^{\circ} \mathrm{W}\right.$ and $\left.15^{\circ} \mathrm{N}-25^{\circ} \mathrm{N}\right)$. During summer $(\mathrm{JJA})$ when dust loads are high, the TOA clear-sky forcing efficiency is estimated to be $-35 \mathrm{Wm}^{-2} \tau^{-1}$, and $-65 \mathrm{Wm}^{-2}$ $\tau^{-1}$ at the surface. In contrast, during winter, the clear-sky TOA forcing efficiency, when dust loads are relatively low and carbonaceous aerosols are present, is $-26 \mathrm{Wm}^{-2} \tau^{-1}$, and $-81 \mathrm{Wm}^{-2} \tau^{-1}$ at the surface. We present in Table 7 the comparison with the clear-sky forcing efficiency obtained in this study.

Since we wanted to be in conditions where the only aerosol was dust, we limit the comparison to the summer season when the single scattering albedo is 0.95 ( $\mathrm{Li}$ et al., 2004), indicative that dust is by far the dominant aerosol component. The much lower winter single scattering albedo of 0.86 obtained during the dry season indicates the presence of carbonaceous aerosols produced by biomass burning. The TOA direct radiative efficiency for clear-sky conditions varies from -45 to $-49 \mathrm{Wm}^{-2} \tau^{-1}$ for the 3 hematite contents discussed here. These values are somewhat higher than the $-35 \pm 3 \mathrm{Wm}^{-2} \tau^{-1}$ measured by Li et al. (2004). In contrast the refractive indices of Patterson et al. (1977) and Volz (1973) lead to a TOA direct radiative efficiency of $-29 \mathrm{Wm}^{-2}$ $\tau^{-1}$.

$\mathrm{Li}$ et al. (2004) measurements report a value of $+30 \pm 4 \mathrm{Wm}^{-2} \tau^{-1}(-35-(-65))$ for the column heating efficiency. This value is intermediate between the two hematite cases with 1.5 and $2.7 \%$ which respectively produced an amount of energy absorbed in the atmospheric column of +22 and $+32 \mathrm{Wm}^{-2} \tau^{-1}$. The Patterson-Volz case (S2) overestimates by a factor of 2 the absorbing efficiency of mineral dust. We could not track this difference to the method used by Patterson et al. (1997) to estimate the refractive index in the visible. Two explanations could not be discarded: either the sample was particularly absorbing due to an unusually high hematite content that seldomly occurs; either it was coated by a stronger absorber than dust.

The ratio of surface to top of atmosphere forcing efficiency also indicates if dust radiative properties are captured. A summer ratio of 1.9 can be computed from Li et al. (2004) measurements. For $S 1$ and $S 1 c$, the summer ratio is in the range 1.5 to 1.7 , close to the measurements, whereas the value of 1.3 for the lower hematite content indicates too little absorption for the case $S 1 b$. In contrast, case $S 2$ when refractive indices from Patterson et al. (1977) and Volz (1973) are used leads to a ratio of 3.0 largely overestimating the observed one (Table 7).

The SHADE experiment took place in September 2000 near Dakar $\left(14^{\circ} \mathrm{N}, 17^{\circ} \mathrm{W}\right)$. Haywood et al. (2003) and Anderson et al. (2005) inferred the DRE from airborne measurements of the radiation. A very intense dust episode was observed on 30 September when optical depth reached 1.49 at $550 \mathrm{~nm}$ at 12:30 UTC. In Anderson et al. (2005) the authors computed the diurnal average radiative forcing efficiency to be $-24 \mathrm{Wm}^{-2} \tau^{-1}$ and found that the ratio between instantaneous and diurnal mean was 3.6. In addition, Haywood et al. (2003) were able to estimate the ratio of surface to top of atmosphere radiative forcing efficiency at 1.6 which allowed 
us to compute the surface value given in Table 7. The simulated DRE for cases $S 1, S 1 b$ and $S 1 c$ lead to values from -16 to $-24 \mathrm{Wm}^{-2} \tau^{-1}$ very close to the diurnal mean observed. The efficiency at the surface are overestimated, from -48 to $-57 \mathrm{Wm}^{-2} \tau^{-1}$ as compared to the inferred value by Haywood et al. (2003) of $-38 \mathrm{Wm}^{-2} \tau^{-1}$. In contrast case $S 2$, Patterson-Volz, leads to a simulated positive forcing efficiency of $+4 \mathrm{Wm}^{-2} \tau^{-1}$ and a very large value at the surface of $-70 \mathrm{Wm}^{-2} \tau^{-1}$ close to 2 times the inferred value. Once again we conclude that such aerosol is much more absorbing than the measurements indicate.

\section{Discussion: is dust warming or cooling the atmo- spheric column?}

Mineral aerosols have a much contrasted radiative effect depending upon the brightness of the underlying surface. Over bare surfaces with a large surface albedo $(>0.30)$ the mineral aerosols will always warm the atmospheric column. Over dark surfaces such as oceans and deciduous forests, where surface albedo is less than 0.15 , the effect of the mineral aerosols is similar to sulphates since it cools the atmospheric column. Over surface albedos in the intermediate range, $0.15<A<0.30$, the sign of the forcing depends mainly on two factors, the size distribution and the mineralogical composition which both determine the single scattering albedo of the particles.

The refractive indices computed in this study are coherent with the measurements. In addition, these refractive indices lead to radiative forcing efficiency close to what was observed over the Western tropical Atlantic. The 3 experiments for which the agreement was obtained were respectively internal mixtures with 1.5 and $2.7 \%$ hematite and the sensitivity case with $1.5 \%$ hematite when a coarse mode is added to the initial size distribution. From these 3 cases, we bracket the global top-of-atmosphere radiative forcing of dust in between values of $-0.40 \mathrm{Wm}^{-2}$ and $-0.24 \mathrm{Wm}^{-2}$. For the surface forcing, the range of these 3 cases is within $-1.11 \mathrm{Wm}^{-2}$ and $-0.92 \mathrm{Wm}^{-2}$. In terms of energy stored in the column per unit optical depth of mineral dust, the energy stored is $+31 \mathrm{Wm}^{-2} \tau^{-1}$ for the Saharan region and $+33 \mathrm{Wm}^{-2} \tau^{-1}$ or the Arabian Peninsula.

\section{Conclusions}

In this paper we examined of mineral aerosol refractive indices. A database of soil mineralogy from arid and semi-arid regions determined the mineralogical composition. The radiative properties of an internal mixture of minerals containing $0.9,1.5$ and $2.7 \%$ hematite were presented that respectively represent: low, median and high absorption.

The top of atmosphere and surface radiative forcing were determined under these assumptions. We found a top of atmosphere radiative forcing in the range from $-0.47 \mathrm{~W} \mathrm{~m}^{-2}$ to $-0.24 \mathrm{~W} \mathrm{~m}^{-2}$ and a surface radiative forcing from -0.81 to $-1.13 \mathrm{~W} \mathrm{~m}^{-2}$. These values indicate that dust is less absorbing than previously assumed (the top of the atmosphere radiative forcing reaches $+0.35 \mathrm{Wm}^{-2}$ and the surface forcing, $-1.44 \mathrm{Wm}^{-2}$, with the same assumptions of dust spatial distributions and clouds when we use refractive indices from Patterson et al., 1977; Volz, 1973). The anthropogenic dust is thought to account for between 10 and $50 \%$ of the total dust load present in the atmosphere. We estimate a top of the atmosphere forcing between -0.03 and $-0.25 \mathrm{Wm}^{-2}$, which is markedly different that the IPCC range of -0.6 to $+0.4 \mathrm{Wm}^{-2}$ (IPCC, 2001).

We compared our results with summer measurements of direct radiative forcing efficiency over the Atlantic region $\left(45^{\circ} \mathrm{W}-15^{\circ} \mathrm{W}\right.$ and from $15^{\circ} \mathrm{N}$ to $\left.25^{\circ} \mathrm{N}\right)$ to measurements taken during the SHADE experiment near Dakar in September 2000. Both cases with median and high hematite contents $(S 1$ and $S 1 c)$ lead to radiative forcing efficiencies that are consistent with the measurements of $\mathrm{Li}$ et al. (2004). In contrast, the case $S 2$ with refractive indices from Patterson et al. (1979) and Volz (1977) overestimates the heating by a factor of 2 and the ratio of surface to top of atmosphere radiative forcing efficiency by a factor of 3 .

Over the tropical Atlantic, the North Indian Ocean and the Sahara region, the atmospheric heating is 3 to 4 times smaller when hematite is considered internally mixed ( $S 1$ case) than in the simulation with the refractive indices from PattersonVolz ( $S 2$ simulation). This finding has important implications regarding the weather forecast simulations.

The disagreements in dust absorption between satellite retrieved effects (Kaufman et al., 2000; Moulin et al., 2000; Haywood et al., 2003), and the modelling studies have been solved through the evaluation of dust refractive indices from the primary minerals that constitute this aerosol. We argue, as these authors did using satellite measurements, that dust is less absorbing than previously thought.

Acknowledgements. This paper is dedicated to Y. Kaufman. The authors would like to acknowledge discussions with O. Dubovik, C. Textor, F. Dentener, O. Boucher, S. Woodward and J. Haywood. We are grateful to the AERONET network for making their measurements available. This work was funded by the European projects Phoenics EVK2-CT-2001-00098 and as part of GEMS FP6-2003-SPACE 1.

Edited by: W. Conant

\section{References}

Alpert, P., Kaufman, Y. J., Shay-el, Y., Tanré, D., da Silva, A., Schubert, S., and Joseph, Y. H.: Dust forcing of climate inferred from correlations between dust data and model errors, Nature, 395, 367-370, 1998.

Anderson, T. L., Charlson, R. J., Bellouin, N., Boucher, O., Chin, M., Christopher, S. A., Haywood, J., Kaufman, Y. J., Kinne, S., Ogren, J. A., Remer, L. A., Takemura, T., Tanré, D., Torres, O., 
Trepte, C. R., Wielicki, B. A., Winker, D. M., and Yu, A. H.: An "A-Train" Strategy for Quantifying Direct Climate Forcing by Anthropogenic Aerosols, Bull. Am. Meteorol. Soc., 86(12), 1795-1809, doi:10.1175/BAMS-86-12-1795, 2005.

Balkanski, Y., Jacob, D. J., Gardner, G. M., Graustein, W. C., and Turekian, K. K.: Transport and residence times of tropospheric aerosols inferred from a global three-dimensional simulation of 210 Pb, J. Geophys. Res., 98, 20 573-20 586, 1993.

Bedidi, A. and Cervelle, B.: Light scattering by spherical particles with hematite- and goethite-like optical properties.Effect of water impregnation, J. Geophys. Res., 98, 11 941-11 952, 1993.

d'Almeida, G. A., Koepke, P., and Shettle, E. P.: Atmospheric aerosols, in Global Climatology and Radiation Characteristics, A. Deepak, Hampton, Va., USA, 1991.

Claquin, T., Schulz, M., and Balkanski, Y.: Modeling the mineralogy of atmospheric dust sources, J. Geophys. Res., 104, $22243-$ $22256,1999$.

Claquin, T., Schulz, M., Balkanski, Y., and Boucher, O.: Uncertainties in modeling the radiative forcing of mineral dust, Tellus, 50B, 491-505, 1998.

d'Almeida, G. A., Koepke, P., and Shettle, E. P.: Atmospheric Aerosols: Global Climatology and Radiative Characteristics, A. Deepak Publishing, 561 pp, 1991.

Deer, W. A., Howie, R. A., and Zussman, J.: An introduction to the rock-forming minerals, New York, John Wiley and Sons, Inc., $528 \mathrm{p}, 1966$.

Dubovik, O., Holben, B., Eck, T., Smirnov, A., Kaufman, Y., King, M., Tanré, D., and Slutsker, I.: Variability of absorption and optical properties of key aerosol types observed in world-wide locations, J. Atmos. Sci., 59, 590-608, 2002.

Egan, W. G. and Hilgeman, T. W.: Optical Properties of Inhomogeneous Materials: Applications to Geology, Astronomy, Chemistry, and Engineering, Academic Press, 235 pp, 1979.

Fouquart, Y. and Bonnel, B.: Computations of solar heating of the Earth's atmosphere: A new parameterization, Beitr. Phys. Atmos., 53, 35-63, 1980.

Giorgi, F. and Chameides, W. L.: Rainout lifetimes of highly soluble aerosols and gases as inferred from simulations with a general circulation model, J. Geophys. Res., 91, 14 367-14376, 1986.

Guelle, W., Balkanski, Y., Schulz, M., Marticorena, B., Bergametti, G., Moulin, C., Arimoto, R., and Perry, K. D.: Modelling the atmospheric distribution of mineral aerosol: Comparison with ground measurements and satellite observations for yearly and synoptic time scales over the North Atlantic, J. Geophys. Res., 105, 1997-2005, 2000.

Guelle, W., Schulz, M., Balkanski, Y., and Dentener, F.: Influence of the source formulation on modeling the atmospheric global distribution of sea-salt aerosol, J. Geophys. Res., 106, 27 50927 524, 2001.

Hauglustaine, D. A., Hourdin, F., Jourdain, L., Filiberti, M.A., Walters, S., and Lamarque, J.-F.: Interactive chemistry in the Laboratoire de Météorologie Dynamique general circulation model: description and background tropospheric chemistry evaluation, J. Geophys. Res., 109, D04314, doi:10.1029/2003JD003957, 2004.

Haywood, J., Francis, P., Osborne, S., Glew, M., Loeb, N., Highwood, E., Tanré, D., Myhre, G., Formenti, P., and Hirst, E.: Radiative properties and direct radiative effect of Saharan dust measured by the C-130 aircraft during Saharan Dust Experiment
(SHADE). 1: Solar spectrum, J. Geophys. Res., 108(D18), 8577, doi:10.1029/2002JD002687, 2003.

Hourdin, F., Musat, I., Bony, S., Braconnot, P., Codron, F., Dufresne, J.-L., Fairhead, L., Filiberti, M.-A., Friedlingstein, P., Grandpeix, J.-Y., Krinner, G., LeVan, P., Li, Z.-X., and Lott, F.: The LMDZ4 general circulation model: climate performance and sensitivity to parametrized physics with emphasis on tropical convection, Clim. Dyn., 19(15), 3445-3482, doi:10.1007/s00382-006-0158-0, 2006.

Hunt, J. M., Wisherd, M. P., and Bonham, L.C.: Infrared absorption spectra of minerals and other inorganic compounds, Anal. Chem., 22, 1478-1497, 1950.

IPCC 2001, Climate Change 2001: The Scientific Basis, Summary for Policy Makers and Technical Summary of the Working Group 1 Report, Intergovernmental Panel on Climate Change, edited by: Houghton, J. T., Ding, Y., Griggs, D. J., Noguer, M., van der Linden, P. J., and Xiaosu, D., Cambridge University Press, Cambridge, UK, 2001.

Kaufman, Y. J., Tanré, D., Dubovik, D. O., Karnieli, A., and Remer, L. A.: Absorption of sunlight by dust as inferred from satellite and ground-based remote sensing, Geophys. Res. Lett., 28, 1479-1482, 2001.

Koven, C. D. and Fung, I.: Inferring dust composition from wavelength-dependent absorption in Aerosol Robotic Network (AERONET) data, J. Geophys. Res., 111, D14205, doi:10.1029/2005JD006678, 2006.

Lafon, S., Rajot, J. L., Alfaro, S. C., and Gaudichet, A.: Quantification of iron oxides in desert aerosol, Atmos Environ, 38(8), 1211-1218, 2004.

Koepke, P., Hess, M., Schult, I., and Shettle, E. P.: Global aerosol data set, report, Max-Planck Inst. für Meteorol., Hamburg, Germany, 1997.

Liao, H. and Seinfeld, J. H.: Radiative forcing by mineral dust aerosols: sensitivity to key variables, J. Geophys. Res., 103(D24), 31 637-31 646, doi:10.1029/1998JD200036, 1998.

Li, F., Vogelmann, A. M., and Ramanathan, V.: Dust aerosol radiative forcing measured from space over the Western Africa, J. Climate, 17(13), 2558-2571, 2004.

Linke, C., Mohler, O., Veres, A., Mohacsi, A., Bozoki, Z., Szab, G., and Schnaiter, M.: Optical properties and mineralogical composition of different Saharan mineral dust samples: a laboratory study, Atmos. Chem. Phys., 6, 3315-3323, 2006, http://www.atmos-chem-phys.net/6/3315/2006/.

Liu, H., Jacob, D. J., Bey, I., and Yantosca, R. M.: Contraints from $210 \mathrm{~Pb}$ and $7 \mathrm{Be}$ on wet deposition and transport in a global threedimensional chemical transport model driven by assimilated meteorological fields, J. Geophys. Res., 106, 12 109-12 128, 2001.

Long, L. L., Querry, M. R., Beli, R. J., and Aiexander, R. W.: Optical properties of calcite and gypsum in crystalline and powdered form in the infrared and the far infrared, Infrar. Phys., 34, 191201, 1993.

Mari, C., Jacob, D. J., and Bechtold, P.: Transport and scavenging of soluble gases in a deep convective cloud, J. Geophys. Res., 105, 22 255-22 268, 2000.

Mishchenko, M. I., Travis, L. D., Kahn, R. A., and West, R. A.: Modeling phase functions for dustlike tropospheric aerosols using a shape mixture of randomly oriented polydisperse spheroids, J. Geophys. Res., 102, 16 831-16847, 1997.

Morcrette, J.-J.: Radiation and cloud radiative properties in the Eu- 
ropean Centre for Medium-Range Weather Forecasts forecasting systems, J. Geophys. Res., 96, 9121-9132, 1991.

Morcrette, J.-J. and Fouquart, Y.: The overlapping of cloud layers in shortwave radiation parameterizations, J. Atmos. Sci., 43, 321328, 1986.

Moulin, C., Gordon, H. R., Banzon, V. F., and Evans, R. H.: Assessment of Saharan dust absorption in the visible from SeaWiFS imagery, J. Geophys. Res., 106(D16), 18 239-18 250, doi:10.1029/2000JD900812, 2001.

Myhre, G. and Stordal, F.: Global sensitivity experiments of the radiative forcing due to mineral aerosols, J. Geophys. Res., 106(D16), 18 193-18 204, doi:10.1029/2000JD900536, 2001.

Patterson, E. M., Filette, D. A., and Stockton, B. H.: Complex index of refraction between 300 and $700 \mathrm{~nm}$ for Saharan aerosols, J. Geophys. Res., 82, 3153-3160, 1977.

Perez, C., Nickovic, S., Baldasano, J. M., Sicard, M., Rocadenbosch, F., and Cachorro, V. E.: A long Saharan dust event over the western Mediterranean: Lidar, Sun photometer observations, and regional dust modeling, J. Geophys. Res., 111, D15214, doi:10.1029/2005JD006579, 2006.

Peterson, J. T. and Weinmar, J. A.: Optical properties of Quartz dust particles at infrared wavelengths, J. Geophys. Res., 74, 69476952, 1969.

Popova, S. I., Tolstych, T. S., and Ivlevn L. S.: Optical constants of $\mathrm{Fe}_{2} \mathrm{O}_{3}$ in the infrared spectral region, Optika Spektrosc., 35, 954-955, 1973.

Querry, M., Osborne, P., Lies, K., Gordon, R., and Coveney, R. M.: Complex refractive index of limestone in the visible and infrared, Appl. Opt., 17, 353-356, 1978.

Reid, E. A., Reid, J. S., Meier, M. M., Dunlap, M. R., Cliff, S. S., Broumas, A., Perry, K., and Maring, H.: Characterization of African dust transported to Puerto Rico by individual particle and size segregated bulk analysis, J. Geophys. Res., 108(D19), 8591, doi:10.1029/2002JD002935, 2003.

Roush, T., Pollack, J., and Orenberg, J.: Derivation of midinfrared $(5-25 \mu \mathrm{m})$ optical constants of some silicates and palagonite, Icarus, 94, 1991.
Schulz, M., Balkanski, Y., Dulac, F., and Guelle, W.: Treatment of aerosol size distribution in a global transport model: Validation with satellite-derived observations for a Saharan dust episode, J. Geophys. Res., 103, 10 589-10 592, 1998.

Shettle, P. E. and Fenn, R. W.: Models for the aerosols of the lower atmosphere and the effects of humidity variations on their optical properties, AFCRL Tech. Report, 79 0214, Research Papers No. 676, Air Force Cambridge Research Laboratory, Hanscom Airforce Base, MA., 100 pp, 1979.

Sokolik I. N., Andronova, A. V., and Jonhson, T. C.: Complex refractive index of atmospheric dust aerosols, Atmos. Environ., 16, 2495-2502, 1993.

Sokolik, I. N. and Toon, O. B.: Direct radiative forcing by anthropogenic airborne mineral aerosols, Nature, 381, 681-683, 1996.

Sokolik, I. N. and Toon, O. B.: Incorporation of mineralogical composition into models of the radiative properties of mineral aerosol from UV to IR wavelengths, J. Geophys. Res., 104(D8), 94239444, doi:10.1029/1998JD200048, 1999.

Steyer, T. R., Day, L., and Huffman, D. R.: Infrared absorption by small amorphous quartz spheres, Appl. Opt., 13, 1586-1590, 1974.

Toon, O. B., Pollack, J. B., and Sagan, C.: Physical properties of the particles composing the martian dust storm of 1971-1972, Icarus, 30, 663-696, 1977.

Tegen, I. and Lacis, A. A.: Modeling of particle size distribution and its influence on the radiative properties of mineral dust aerosol, J. Geophys. Res., 101, 19 237-19244, 1996.

Volz, F. E.: Infrared optical constants of ammonium sulphate, Saharan dust, volcanic pumice, and flyash, Appl. Opt., 12, 564-568, 1973.

Woodward, S.: Modeling the atmospheric life cycle and radiative impact of mineral dust in the Hadley Centre climate model, J. Geophys. Res., 106(D16), 18 155-18 166, doi:10.1029/2000JD900795, 2001. 